\title{
Preface
}

\section{Digital Technologies in Oral and Maxillofacial Surgery}

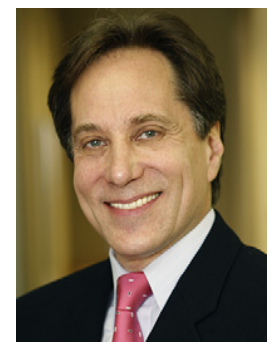

Gary Orentlicher, DMD

Guest Editor

Those of us who have not been stranded on a desert island for the last two decades realize how computers and digital technologies have crept into our lives. How often do we ask ourselves the question, "How did I ever live without this?" Smart phones, portable computers, the Internet, e-mail, digital cameras, and endless other examples of technological wizardry have altered our personal lives. Similarly, the fields of dentistry, medicine, and oral and maxillofacial surgery have been changed forever by new technologies.

This issue of the Atlas of the Oral and Maxillofacial Surgery Clinics was designed as both an introduction to these new and exciting technologies and a knowledge base to integrate these technologies into clinical practice and patient care. The authors in this issue have provided examples of how they have applied these technologies. Once the reader has mastered them, the skill, imagination, and creativity of the clinician will stimulate new and innovative uses, and their use of this technology will flourish.

The text is organized to provide the reader first with a knowledge foundation in CT/CBCT scanners and then computer-aided manufacturing technologies. The articles that follow cover the current use of these innovative digital technologies in the full scope of oral and maxillofacial surgery practice; dentoalveolar surgery, dental implant planning and placement, trauma, pathology and reconstruction, orthognathic/craniofacial/temporomandibular joint applications, cosmetic facial implants, and extraoral facial reconstruction. The authors are a well-known group of educators, clinicians, innovators, and forward thinkers who have extended themselves and their time graciously to this project. For this, I can't thank them enough.

Oral and maxillofacial surgeons take for granted the lessons, instrumentation, and techniques painstakingly developed and tested by the past pioneers of our specialty. So too will there be a new generation of "pioneers" who largely will be using these new technologies, along with others yet to be developed, to continue the advancement of our specialty. The ultimate goal is and will always be the same-better treatment outcomes for our patients.

Gary Orentlicher, DMD

Private Practice, New York Oral Maxillofacial, and Implant Surgery 495 Central Park Avenue, Suite 201

Scarsdale, NY 10583, USA

E-mail address: drgaryo@yahoo.com 